\title{
LOW-STAKES ASSESSMENTS: AN EFFECTIVE TOOL TO IMPROVE MARKS IN HIGHER-STAKES SUMMATIVE ASSESSMENTS? EVIDENCE FROM COMMERCE STUDENTS AT A SOUTH AFRICAN UNIVERSITY
}

\author{
J. M. Ontong \\ School of Accountancy \\ Stellenbosch University \\ Stellenbosch, South Africa \\ https://orcid.org/0000-0001-5097-8988
}

\section{ABSTRACT}

The concept of practice makes perfect is often embedded in the decision to provide students with low-stakes formative and summative assessments with the intention of providing practice for higher-stakes summative assessments. The assumption is that participation in low-stakes formative and summative assessments will result in higher grades obtained in subsequent higherstakes summative assessments. Using a quantitative approach, this study examined whether participation in low-stakes formative and summative assessments resulted in higher marks obtained in higher-stakes summative assessments. The findings of the study suggest that although in the majority of cases the participation of students in low-stakes formative or summative assessments resulted in higher marks obtained in subsequent summative assessments, an important planning consideration is the scope of the formative and summative assessments. The study found that when a low-stakes formative assessment does not cover the majority of the scope of the higher-stakes summative assessment, firstly, the participation percentage decreases significantly in comparison to other assessments that cover a larger portion of the scope of the following assessment. Secondly, the findings suggest that having a small, perhaps trivial, stake in terms of an assessment's contribution to final mark versus no stake has a significant impact on the students' participation levels, as well as the potential value added from participation in such assessments for future assessments. The findings also show that the quantity of low-stakes assessments does not necessarily need to be increased to increase the effectiveness of these interventions; instead, particular focus should be placed on ensuring that formative assessments cover the scope sufficiently of higher-stakes summative assessments if the intended purpose of these is to assist in improving marks in higher-stakes assessments. The findings suggest that the design of low-stakes formative and summative assessments are integral into the potential contribution these have on student performance in subsequent higher-stakes summative assessments.

Keywords: Accounting, first-year students, formative assessments, summative assessments 


\section{INTRODUCTION}

The concept of practice makes perfect, at its core, suggests that when students are given the opportunity to practise their capabilities, they will develop their skills and knowledge of certain subject areas (Brooks 2018). A critical review of existing literature on the use of formative assessments provides empirical evidence that the use of formative assessments results in improved educational outcomes (Dunn and Mulvenon 2009). Formative assessment has been defined as "activities undertaken by teachers and by their students in assessing themselves that provide information to be used as feedback to modify teaching and learning activities" (Black and Wiliam 2010). Formative assessment therefore encompasses a host of tools that provide feedback to teachers and students to help students learn more effectively (Dixson and Worrell 2016). Participation in formative assessments, however, varies significantly within the firstyear Financial Accounting module, which resulted in the question being asked, does the benefits of formative assessments not to outweigh potential opportunity costs?

The practise of using online formative assessments, commonly in low stakes assessments is common practise in higher education, the literature however suggests that data on the effectiveness of such interventions is limited (Velan et al. 2008). Dunn and Mulvenon (2009) note that using formative assessments and other tools in lectures are expected to result in improved pedagogical practices and instructional outcomes. Curtis (2011) notes that formative assessments are one of the most effective classroom interventions for improving student learning outcomes across a variety of education settings; the accounting education literature is, however, almost bereft of any work related to formative assessment (Curtis 2011). Curtis (2011) suggests that the performing of multiple sequenced tasks, in the form of formative assessments may be one of the higher effective measures for identifying areas in which students require intervention in the coursework. For the purposes of this study, formative assessments in the form of online multiple-choice questions based on the course work were examined. These formative assessments are completed against time, and students are given feedback after the assessment as to whether or not their attempt was correct. Similarly, low-stakes online multiplechoice question summative assessments are also preformed prior to higher-stakes main summative assessments.

The improvement and increased prevalence of the use of technology in education has to a large extent transformed the assessment landscape, limitations to the design of assessments, such as being in a certain place and performing an assessment only at a certain time have been surmounted (Khairil and Mokshein 2018). Formative assessments for the purposes of this study consisted of online assessments.

The research objective of this study was twofold; firstly, to understand whether 
participation in formative assessments (which do not count for marks) prior to main ${ }^{1}$ summative assessments contributed to higher marks achieved in main summative assessments (which do count for marks), and, secondly, to understand whether participation in smaller-weighting summative assessments (which do count for marks) prior to main summative assessments contributed to higher marks achieved in main summative assessments (which do count for marks).

The main contribution of this research is to understand the effect of participation in both formative assessments (which do not count for marks) and low-stakes summative assessments (which do count for marks) on the marks achieved in higher-stakes main summative assessments. This study contributes to the existing literature by providing insights into commerce students' participation in lower-stakes assessments, as well as providing lecturers and other course developers with insights into the use of formative assessments and low-stakes summative assessments.

\section{Background to the introductory Financial Accounting module}

The module is a full-year module offered by Stellenbosch University and focuses on an introduction to financial accounting. The target group for this study comprised the students enrolled in the 2018 and 2019 Financial Accounting 188 module. The module was offered to a group of approximately 1200 students in both years. The module is offered in both English and Afrikaans.

The remainder of this study is structured as follows: the introduction is followed by a review of the existing literature, which provides an overview of existing studies in this field. This leads to a descriptive and statistical analysis of the data. The article concludes with a summary of the findings and a conclusion.

\section{LITERATURE REVIEW}

The literature review provides an overview of the concepts of formative and summative assessments. As noted below, although there is extensive literature on the use of formative and summative assessments, literature on the use of formative assessments and low-stakes summative assessments in accounting education remains limited.

The concept of evaluation through assessment plays a fundamental role in education. Scriven $(1967,41)$ notes that the evaluation of students is critical as "it may have a role in the on-going improvement of the curriculum". Scriven $(1967,43)$ proposes the use of the terms “"formative' and 'summative' evaluation to qualify evaluation in these roles". The purpose of assessments in terms of the value contributed by assessments has received increased attention 
(Holroyd 2000). The literature suggest that the pedagogical practises of educators is to create an environment where students learning is assessment-led, meaning students often focus only on studying what will be assessed (Heywood 2000). Boud (1988) further states that the assessment practises of educators need to be an integral part of the learning process of students, arguing that assessments may possibly have one of the most significant impacts on what students decide to revise and study and consequently be a driver for learning. Biggs (1999) argues that assessments, in the form of summative and formative should reinforce learning and not be the lead driver for learning. Included as the first rule in Ramsden's (1992) 14 rules for better assessment in higher education is: "link assessment to learning ... assess during the experience of learning as well as at the end of it". The literature also points towards increased use of "post-positive" approaches to assessments, where an alignment of active learning processes and interventions such as the effective use formative assessments are increasingly being searched for (Elton and Johnston 2002, 204).

\section{Formative assessments}

Formative assessments vary significantly in nature, format, and scope, depending on the nature of the subject being evaluated. For the purposes of this study, Black and William's $(2010,82)$ definition of formative assessments will be used, namely that they are "activities undertaken by teachers and by their students in assessing themselves that provide information to be used as feedback to modify teaching and learning activities". Wiggins $(1998,7)$ notes that "the aim of [formative] assessment is primarily to educate and improve student performance, not merely to audit it".

The importance of formative assessments in evaluation has received attention in the literature. Rowntree (1985) notes that formative assessments are considered the lifeblood of learning. Black and William (2010) state that formative assessment is an essential component of classroom work and can improve student achievement. Nicol and MacFarlane-Dick (2006) suggest that using improved formative assessments as an academic intervention can potentially increase academic success, the effect however of formative assessments on students marks in summative assessments has not been explored extensively in the literature as mixed results are observed. Murphy and Stanga (1994) found that for an introductory income tax course using an experiment, although the experimental group had a higher mean performance on the cumulative final examination, the difference was not statistically significant. The literature suggests that the design of formative assessment in contrast to the formative assessment's mark contribution has a greater impact on achieving academic success, whereas summative assessments, which are often compulsory in nature, are a greater indicator of students' ability to meet assessment 
criteria. (Aisbitt and Sangster 2005; Knight 2001).

Research notes that there is untapped potential for the use of formative assessments to assist students' learning (Velan et al. 2008). However, in a study where the authors analysed to what extent participation and performance in formative assessment are associated with positive academic outcomes of pre-graduate students of health sciences, the authors noted that causal relationships between formative and summative assessment could not be established from the research (Carrillo-de-la-Peña et al. 2009). There are therefore mixed results regarding the contribution that formative assessments make in terms of the effect on summative assessments.

Although the positive contribution of formative assessment is noted, the literature also notes a decline in the use of formative assessment. Gibbs and Simpson (2005) state that in the United Kingdom, a traditional characteristic of teaching in higher education has been the frequent use of formative assignments with the provision of detailed personalised feedback on these assignments. The frequency of such formative assignments has been noted to often be weekly, with many students arguing that the formative assessments were almost the only teaching that many Oxbridge students experienced; in other words, teaching meant giving feedback on essays (Gibbs and Simpson 2005). The use of formative assessments was quite limited, and the only summative assessments often consisted of final examinations (Gibbs and Simpson 2005). The literature suggests that the planning of formative assessments is key to obtaining a successful contribution from these interventions.

\section{Summative assessments}

The literature suggests that, unlike formative assessments, which are generally used to provide feedback to students and teachers, summative assessments are generally higher-stakes assessments and are used to gain a final assessment of how much learning has taken place; that is, being able to assess how much a student knows (Gardner 2010). Summative assessments are almost always graded, are typically less frequent, and occur at the end of segments of instruction (Dixson and Worrell 2016). The purpose of summative assessments is to assess learning, which is how well a student has acquired knowledge and skills and developed cognition at a specific point in time (Qadir et al. 2020).

The literature suggests that the consensus is the use of multiple summative assessments may be a time-consuming process in terms of setting these assessments, the benefits of these assessments to the student far outweigh the associated cost. The results should be of interest to academics who are concerned about assessment and its impact on behaviour (Trotter 2006). The question, however, arises whether low-stakes summative assessment make a greater contribution to student marks in comparison to formative assessments. 
Trotter (2006) notes that the consensus from students, based on interviews and questionnaires is that the use of continuous summative assessments is viewed as an beneficial practise to students in terms of achieving learning outcomes. The students further noted that the use of continuous summative assessments provided them with motivation to focus on achieving the course outcomes (Trotter 2006). It is further noted by the students that feedback on assessments provided to students further motivates students to improve or maintain their performance, highlighting the importance of feedback on both summative and formative assessments (Trotter 2006). The literature is, however, limited on the use of low-stakes summative assessments as a way to improve scores in higher-stakes summative assessments.

\section{Overall summary}

Getting the focus of assessments right, noteworthy formative assessment has been a focal area in the literature for some time (Wiliam 2006). Ayala et al. (2008) point out the critical importance of collaboration and professional development aimed at enabling teachers to reconceptualise the role of assessments in their teaching, linking formative assessments to overall goals, and providing a learning trajectory as reference for teachers to locate students' ideas in the trajectory and providing feedback accordingly (Ayala et al. 2008).

The use of formative and summative assessments have a significant influence on students' learning, including being important for providing students with feedback on whether they are achieving learning outcomes as well as providing motivation for potential future performance in other assessments (Marriott and Lau 2008). Innovation in assessment as a result of technological advancement has resulted in various opportunities for innovative ways to set up both formative and summative assessments. (Marriott and Lau 2008). Feedback from students substantiate claims that assessments play a significant role in the teaching/learning process (Marriott and Lau 2008). This study therefore attempted to first analyse the impact of formative assessments and low-stakes summative assessments on higher-stakes summative assessments in order to quantitatively assess the role of additional assessments in an accounting education environment, and furthermore to investigate whether the scope of such assessments has a significant impact on the contribution made by such assessments.

\section{RESEARCH METHODOLOGY}

The methodology utilised quantitative data obtained via class lists for students enrolled in 2018 and 2019 in a first-year Financial Accounting module. Ethical clearance was obtained for this study using the appropriate ethical clearance processes. 


\section{Quantitative analysis}

Statistical analysis was performed using the Statistica software package. Statistical analysis involved performing descriptive analysis of the dataset, as well as seven separate tests based on four higher-stakes main assessments (weighting of $15 \%$ or more each) during the year and four other assessments; namely two formative assessments and two smaller low-stakes summative assessments (weighting of $2.5 \%$ each). The composition of the assessments evaluated are displayed in Table 1.

Table 1: Assessments timing, weighting to final marks, and types (applicable to both 2018 and 2019)

\begin{tabular}{|c|c|c|}
\hline Period & $\begin{array}{l}\text { Weighting to } \\
\text { final mark }\end{array}$ & Assessment type \\
\hline March & $0 \%$ & $\begin{array}{l}\text { Low-stakes formative assessment } \\
\text { Format: Unsupervised online quiz } \\
\text { Scope: Chapters } 1 \text { to } 10 \\
\text { Estimated scope of subsequent main assessment: } 90 \%\end{array}$ \\
\hline March & $15 \%$ & $\begin{array}{l}\text { Higher-stakes summative assessment } \\
\text { Format: Three-hour written supervised assessment } \\
\text { Scope: Chapters } 1 \text { to } 10 \text { plus a portion of Chapter } 11\end{array}$ \\
\hline May & $2.5 \%$ & $\begin{array}{l}\text { Low-stakes summative assessment } \\
\text { Format: Unsupervised online quiz } \\
\text { Scope: Chapters } 10 \text { to } 12 \\
\text { Estimated scope of subsequent main assessment: } 75 \%\end{array}$ \\
\hline June & $20 \%$ & $\begin{array}{l}\text { Higher-stakes summative assessment } \\
\text { Format: Three-hour written supervised assessment } \\
\text { Scope: Chapters } 10 \text { to } 13 \text { and } 20\end{array}$ \\
\hline August & $2.5 \%$ & $\begin{array}{l}\text { Low-stakes summative assessment } \\
\text { Format: Unsupervised online quiz } \\
\text { Scope: Chapter } 13 \\
\text { Estimated scope of subsequent main assessment: } 25 \%\end{array}$ \\
\hline September & $20 \%$ & $\begin{array}{l}\text { Higher-stakes summative assessment } \\
\text { Format: Three-hour written supervised assessment } \\
\text { Scope: Chapters } 13 \text { to } 17\end{array}$ \\
\hline October & $0 \%$ & $\begin{array}{l}\text { Low-stakes formative assessment } \\
\text { Format: Unsupervised online quiz } \\
\text { Scope: Chapters } 17 \text { and } 19 \\
\text { Estimated scope of subsequent main assessment: } 20 \%\end{array}$ \\
\hline November & $40 \%$ & $\begin{array}{l}\text { Higher-stakes summative assessment } \\
\text { Format: Three-hour written supervised assessment } \\
\text { Scope: Chapter } 1 \text { to } 20\end{array}$ \\
\hline
\end{tabular}

The research questions were as follows:

- Research Question 1 (RQ1): What levels of participation are achieved in formative assessments that do not count for marks versus summative assessments?

- $\quad$ Research Question 2 (RQ2): Does completing a formative assessment (which does not count for marks) result in higher marks achieved in higher-stakes main summative assessment?

- $\quad$ Research Question 3 (RQ3): Does completing a lower-stakes summative assessment result in higher marks achieved in a higher-stakes main assessment? 
RQ1 was answered by means of descriptive analysis of the participation in assessments throughout the year. RQs 2 and 3 were answered by performing least squares means tests, namely arithmetic means computed by Statistica using a linear model, namely an analysis of variance (ANOVA), per the scenario below.

The least squares means tests were performed on the following combinations of assessments:

1) The March formative and summative assessments (RQ2).

2) The May and June summative assessments (RQ3).

3) The May and June summative assessments controlling for the March assessment (RQ3).

4) The August and September summative assessments (RQ3).

5) The August and September summative assessments controlling for the June assessment (RQ3).

6) The October formative and November summative assessment (RQ2).

7) The October formative and November summative assessment controlling for the September assessment (RQ2).

\section{FINDINGS}

The findings are presented in terms of the research questions. Firstly, descriptive analysis was performed in order to answer RQ1, which is followed by statistical analysis in order to answer RQ2 and RQ3.

\section{Descriptive analysis}

The results of the descriptive analysis are displayed in Table 2. The results show that the participation percentages in assessments, with the exception of the formative assessment in October, ranged between 84 per cent and 94 per cent, which reflect a high participation rate. Based on these findings, it is suggested that participation in a formative assessment that does not count for marks is volatile based on various potential factors. Participation in summative assessments remains relatively constant regardless as to whether the assessment is a higherstakes or low-stakes assessment. The timing further suggests that students are more willing to engage in formative assessments that do not count for marks earlier in the module and less likely to engage in formative assessments that do not count for marks later in the module.

The findings suggest that the nature of the formative assessment being online does not have a significant impact on participation rates in the first half of the year. It is suggested, however, as the formative assessment in the second semester was online, that this perhaps 
contributed to the low participation as an in-person written formative assessment may have had greater participation. This was identified as an area for further evaluation and future research. The participation is suggested to perhaps be as a result of the perceived benefit by students of completing the formative assessment versus the potential costs, such as spending time on other modules closer to higher-stakes assessments. As the scope of the formative assessment prior to the November higher-stakes assessment only covered a limited amount of work, this suggests that the content covered in a formative assessment plays a significant role in the participation levels of these assessments. These findings suggest that students perhaps consider the benefits of completing a formative assessment not to be associated with higher marks in higher-stakes summative assessments; this will be examined further in the remaining part of the findings section.

Table 2: Descriptive analysis of population and participation

\begin{tabular}{|c|c|c|c|c|}
\hline Assessment type & Period & Valid N & Population N & $\begin{array}{c}\text { Participation } \\
\text { percentage }\end{array}$ \\
\hline \multirow[t]{2}{*}{ Low-stakes formative assessment } & March 2019 & 1147 & 1217 & 94 \\
\hline & March 2018 & 1171 & 1191 & 98 \\
\hline \multirow{2}{*}{$\begin{array}{l}\text { Higher-stakes summative } \\
\text { assessment }\end{array}$} & March 2019 & 1148 & 1217 & 94 \\
\hline & March 2018 & 1170 & 1191 & 98 \\
\hline \multirow{2}{*}{$\begin{array}{l}\text { Low-stakes summative } \\
\text { assessment }\end{array}$} & May 2019 & 1086 & 1217 & 89 \\
\hline & May 2018 & 1136 & 1191 & 95 \\
\hline \multirow{2}{*}{$\begin{array}{l}\text { Higher-stakes summative } \\
\text { assessment }\end{array}$} & June 2019 & 1069 & 1217 & 88 \\
\hline & June 2018 & 1127 & 1191 & 95 \\
\hline \multirow{2}{*}{$\begin{array}{l}\text { Low-stakes summative } \\
\text { assessment }\end{array}$} & August 2019 & 1073 & 1217 & 88 \\
\hline & August 2018 & 1127 & 1191 & 95 \\
\hline \multirow{2}{*}{$\begin{array}{l}\text { Higher-stakes summative } \\
\text { assessment }\end{array}$} & September 2019 & 1045 & 1217 & 86 \\
\hline & September 2018 & 1081 & 1191 & 91 \\
\hline \multirow[t]{2}{*}{ Low-stakes formative assessment } & October 2019 & 301 & 1217 & 25 \\
\hline & October 2018 & 407 & 1191 & 34 \\
\hline \multirow{2}{*}{$\begin{array}{l}\text { Higher-stakes summative } \\
\text { assessment }\end{array}$} & November 2019 & 1022 & 1217 & 84 \\
\hline & November 2018 & 1012 & 1191 & 85 \\
\hline
\end{tabular}

\section{Analysis of the impact of participation in a formative assessment that does not count for marks or a low-stakes summative assessment on a higher-stakes summative assessment}

The following section investigates the impact of the various formative assessments that did not count for marks or low-stakes summative assessments on marks achieved in a higher-stakes summative assessment. The study examined the relationship between the four higher-stakes main assessments during the year and the immediately preceding formative assessment of lowstakes summative assessment. 


\section{March assessment marks versus completion of the formative assessment}

As displayed in Table 3, 1148 (2019) and 1170 (2018) students completed the March higherstakes main summative assessment. Of these, 1127 (2019) and 1151 (2018) completed the formative assessment prior to the March higher-stakes main assessment. Based on the scores achieved in the March main assessment, the mean scores of 65.305 (2019) and 60.499 (2018) for students who completed the formative assessment are significantly higher than the mean scores of 49.952 (2019) and 43.342 (2018) achieved by those who did not complete the formative assessment. This finding suggests that participation in a low-stakes formative assessment prior to the higher-stakes summative assessment where the scope is more or less the same had a significant impact on students' performance in the subsequent assessment.

Table 3: March main assessment summarised data

\begin{tabular}{|l|r|r|r|}
\hline \multicolumn{1}{|c|}{ Completed the formative assessment } & N & Mean & Standard deviation \\
\hline $\mathbf{2 0 1 9}$ & 1148 & 65.024 & 18.005 \\
\hline Total & 1127 & 65.305 & 17.915 \\
\hline Yes & 21 & 49.952 & 16.693 \\
\hline No & 1170 & 60.220 & 16.851 \\
\hline $\mathbf{2 0 1 8}$ & 1151 & 60.499 & 16.761 \\
\hline Total & 19 & 43.342 & 13.610 \\
\hline Yes & &
\end{tabular}

The results of the boxplot graphs as displayed in Figure 1 indicate that although the mean scores were higher for the group that completed the formative assessment, the range of marks achieved was wider and consequently there were students who completed the formative assessment and achieved a lower mark than their counterparts who did not take the quiz. In order to control for the students' academic ability for the remainder of the tests performed, the tests were performed including controlling for the previous assessment mark in order to account for this.

\section{June assessment marks versus completion of the low-stakes summative assessment}

As displayed in Table 4, 1069 (2019) and 1127 (2018) students completed the June higherstakes main summative assessment. Of these, 1019 (2019) and 1085 (2018) completed the low-stakes summative assessment prior to the June higher-stakes main assessment. Based on the scores achieved in the June main assessment, the mean scores of 52.818 (2019) and 57.419(2018) for students who completed the low-stakes summative assessment were 


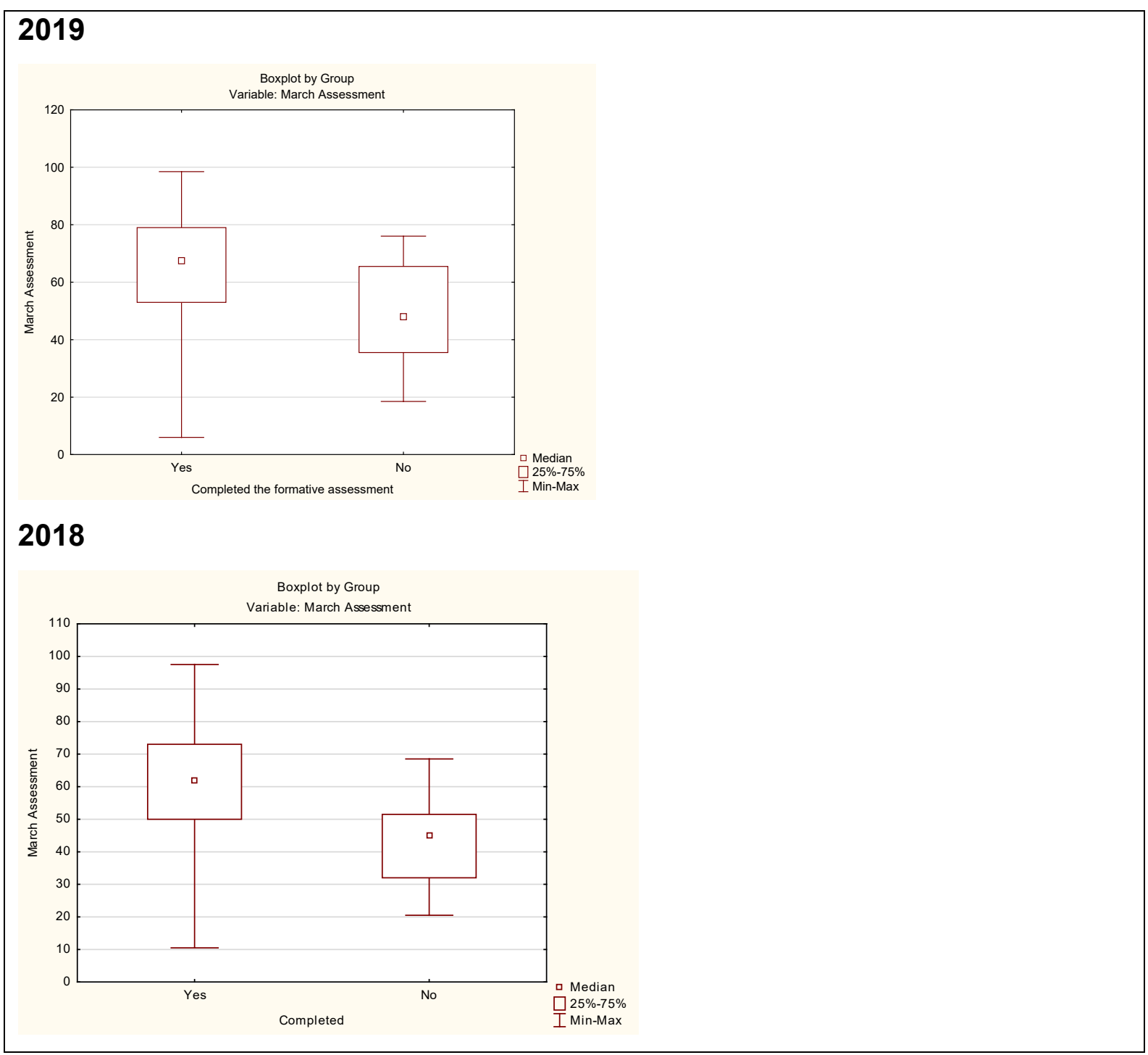

Figure 1: Boxplot of March assessment marks

Table 4: June main assessment summarised data

\begin{tabular}{|l|r|r|c|}
\hline Completed the low-stakes summative assessment & N & Mean & Standard deviation \\
\hline $\mathbf{2 0 1 9}$ & 1069 & 53.240 & 20.331 \\
\hline Total & 1019 & 53.818 & 20.219 \\
\hline Yes & 50 & 41.460 & 19.179 \\
\hline No & 1127 & 56.953 & 20.668 \\
\hline $\mathbf{2 0 1 8}$ & 1085 & 57.419 & 20.520 \\
\hline Total & 42 & 44.929 & 21.095 \\
\hline Yes & & \\
\hline No &
\end{tabular}

significantly higher than the mean scores of 41.460 (2019) and 44.929 (2018) achieved by those who did not complete the low-stakes summative assessment. This finding suggests that participation in a low-stakes summative assessment prior to the higher-stakes summative assessment where the scope is more or less the same had a significant impact on students' 
performance in the subsequent assessment.

When comparing the two groups with ANOVA, the assumption is that the data are normally distributed and that the variances of the two groups are homogeneous, which means that the variances are similar. The ANOVA conducted for the remainder of the study was performed on a 95 per cent confidence level. The sample size for the "yes" groups was significantly larger that the "no" groups; consequently, the widths of the 95 per cent confidence intervals for the means of the "yes" groups will be much less than the widths of the 95 per cent confidence intervals for the means of the "no" groups.

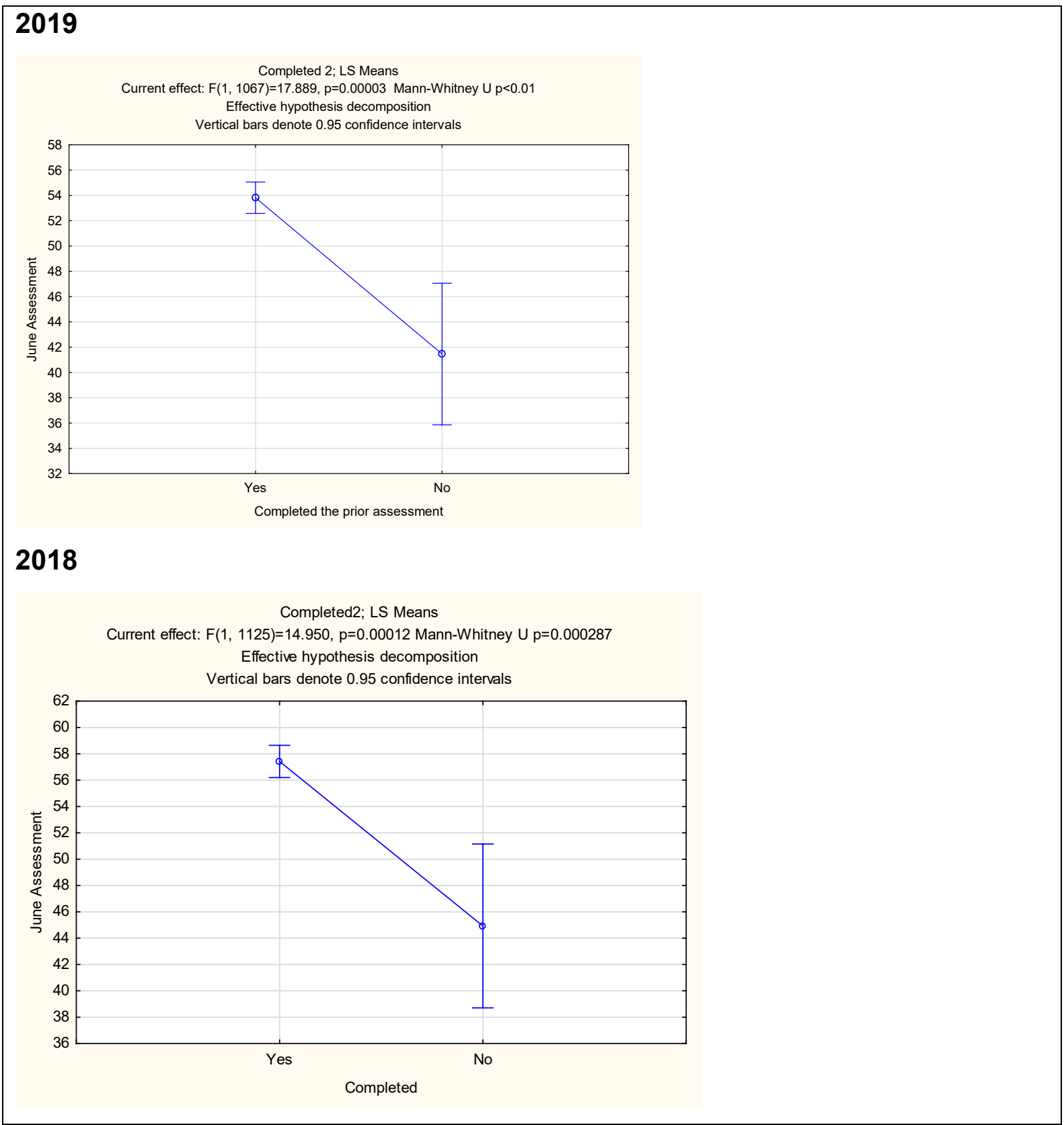

Figure 2: ANOVA results (not controlling for previous main assessment mark) 
Similar to the results above, the ANOVA for the June higher-stakes main assessment, as displayed in Figures 2 and 3, shows that the students who participated in the low-stakes summative assessment achieved higher mean marks, with and without controlling for the previous assessments marks. This suggests that students who completed low-stakes summative assessments obtained a benefit because of engaging in such assessments.

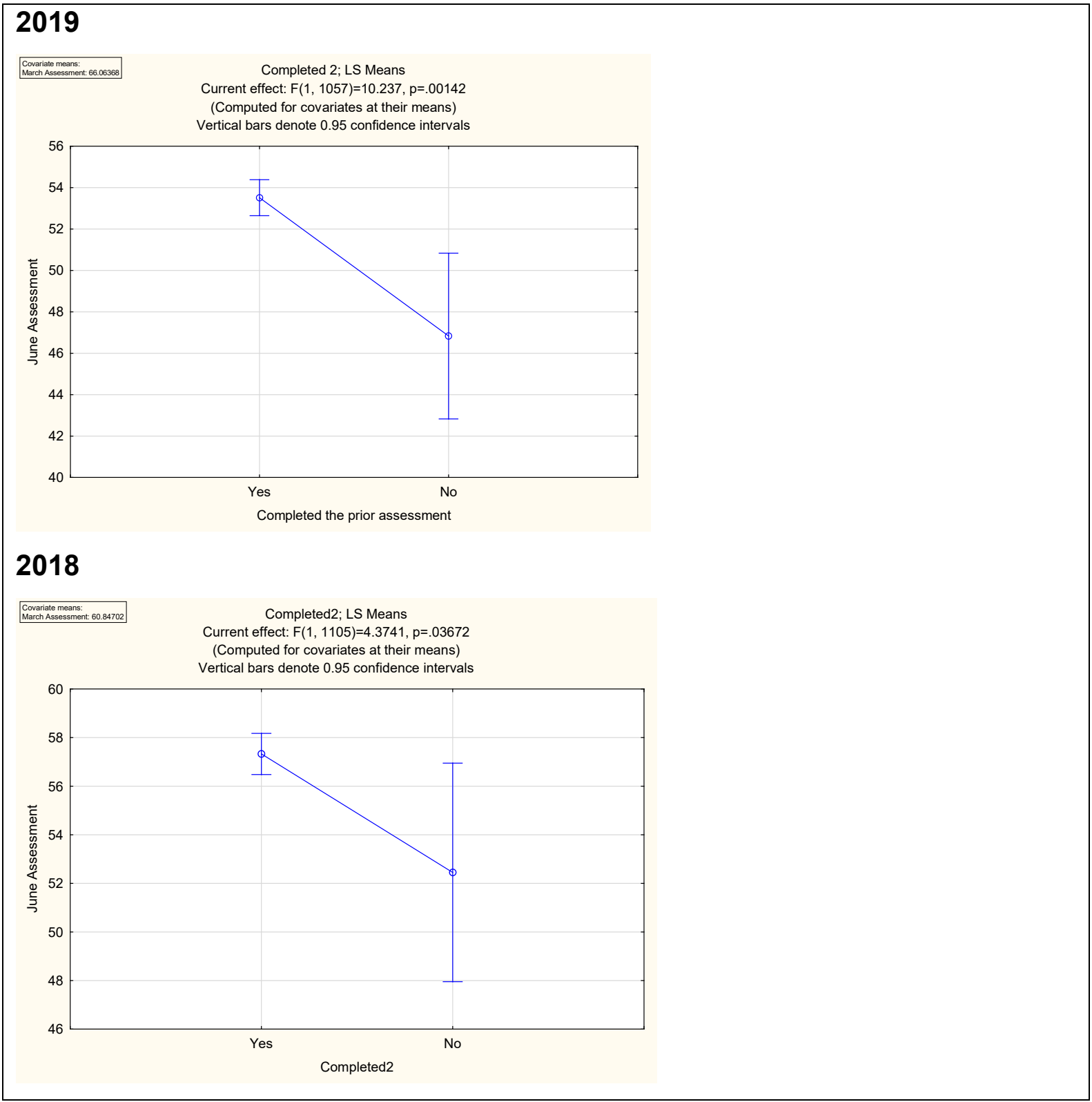

Figure 3: ANOVA results (controlling for previous main assessment mark)

\section{September assessment marks versus completion of the low-stakes summative assessment}

As displayed in Table 5, 1045 (2019) and 1081 (2018) students completed the September higher-stakes main summative assessment. Of these, 990 (2019) and 1049 (2018) completed 
the low-stakes summative assessment prior to the September higher-stakes main assessment. Based on the scores achieved in the September main assessment, the mean scores of 62.418 (2019) and 58.021 (2018) for students who completed the low-stakes summative assessment were significantly higher than the mean scores of 53.245 (2019) and 50.563 (2018) achieved by those who did not complete the low-stakes summative assessment. This finding suggests that participation in a low-stakes summative assessment prior to a higher-stakes summative assessment where the scope is more or less the same had a significant impact on students' performance in a subsequent assessment.

Table 5: September main assessment summarised data

\begin{tabular}{|l|r|r|r|}
\hline Completed the low-stakes summative assessment & N & Mean & Standard deviation \\
\hline $\mathbf{2 0 1 9}$ & 1045 & 61.935 & 19.435 \\
\hline Total & 990 & 62.418 & 19.218 \\
\hline Yes & 55 & 53.245 & 21.381 \\
\hline No & \multicolumn{5}{|l|}{} \\
\hline $\mathbf{2 0 1 8}$ & 1081 & 57.800 & 18.491 \\
\hline Total & 1049 & 58.021 & 18.436 \\
\hline Yes & 32 & 50.563 & 19.105 \\
\hline No & & & \\
\hline
\end{tabular}

Similar to the results above, the ANOVA for the September higher-stakes main assessment, as displayed in Figures 4 and 5, show that the students who participated in the low-stakes summative assessment obtained higher mean marks, with and without controlling for the previous assessments marks. Figure 5 shows, however, that for 2018, when controlling for the previous higher-stakes assessment mark, that there is no significant variance between the students who completed the assessment and those who did not. In 2019, the results, however, indicate that there was a significant variance in marks based on participation. The results are therefore mixed in terms of the effectiveness of this assessment. Noteworthy is that although the scope of this low-stakes summative assessment only covered a small portion of the subsequent higher-stakes summative assessment's scope, the results demonstrate that only in certain scenarios will a benefit be obtained from participating in an assessment that does not cover all the work. This suggests that students who complete low-stakes summative assessments obtain a benefit because of engaging in such assessments only in certain circumstances. It is suggested that the scope of the work covered plays a significant role in the effectiveness of the assessment. This is further demonstrated in the results for the November assessment. 


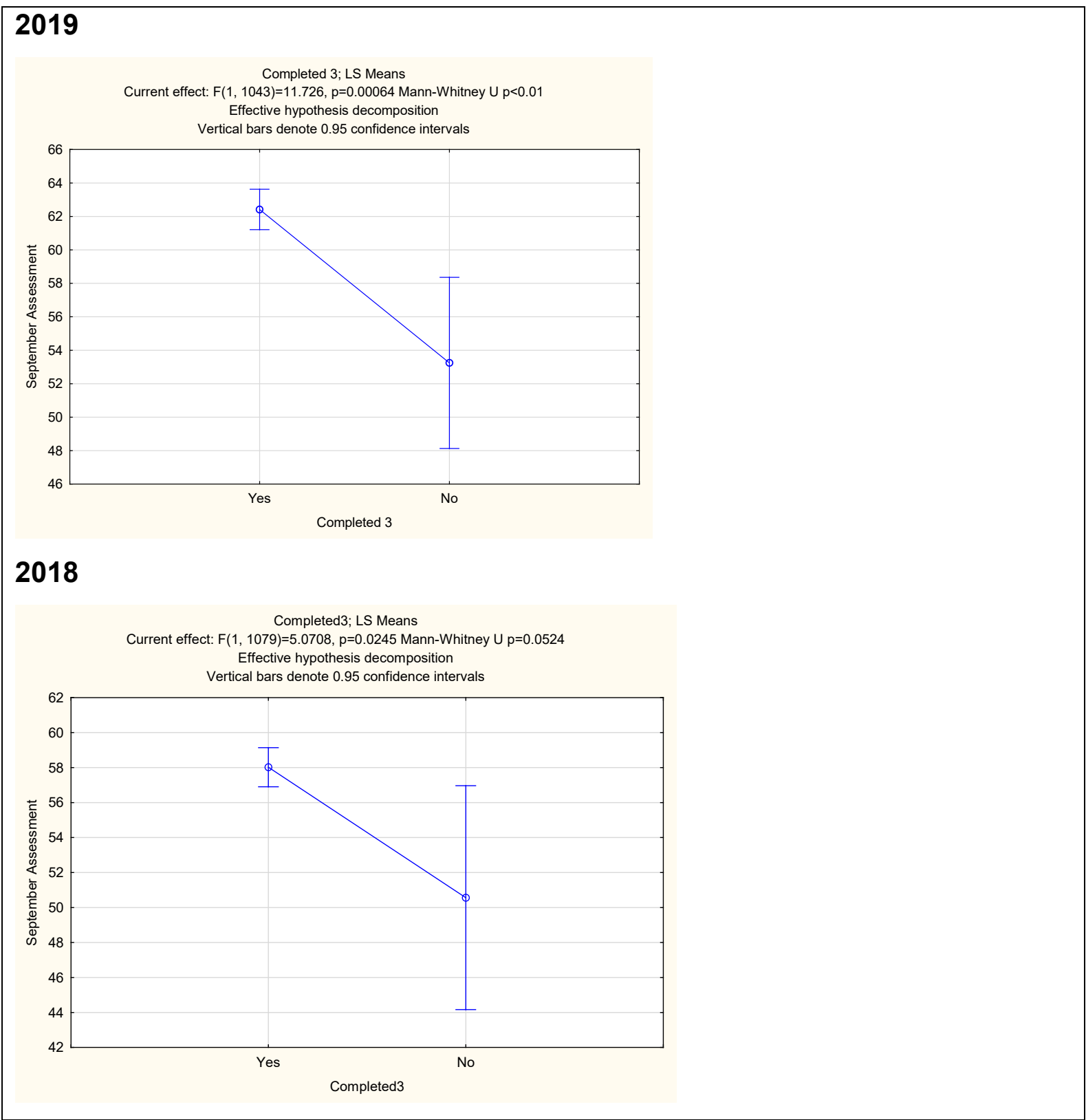

Figure 4: ANOVA results (not controlling for previous test main assessment mark)

\section{November assessment marks versus completion of the formative assessment}

As displayed in Table 6, 1022 students completed the November higher-stakes main summative assessment. Of these, 280 completed the formative assessment prior to the November higher-stakes main assessment. Based on the scores achieved in the September main assessment, the mean score of 56.366 for students who completed the formative assessment was marginally higher than the mean score of 55.825 achieved by those who did not complete the low-stakes summative assessment. The findings therefore suggest that, in most scenarios, the students who completed formative assessments and low-stakes summative assessments achieved on average higher marks than their counterparts who did not. This is not necessarily 
valid for all assessments, which suggests that other factors such as time pressure may play a role in whether a student completes these assessments.

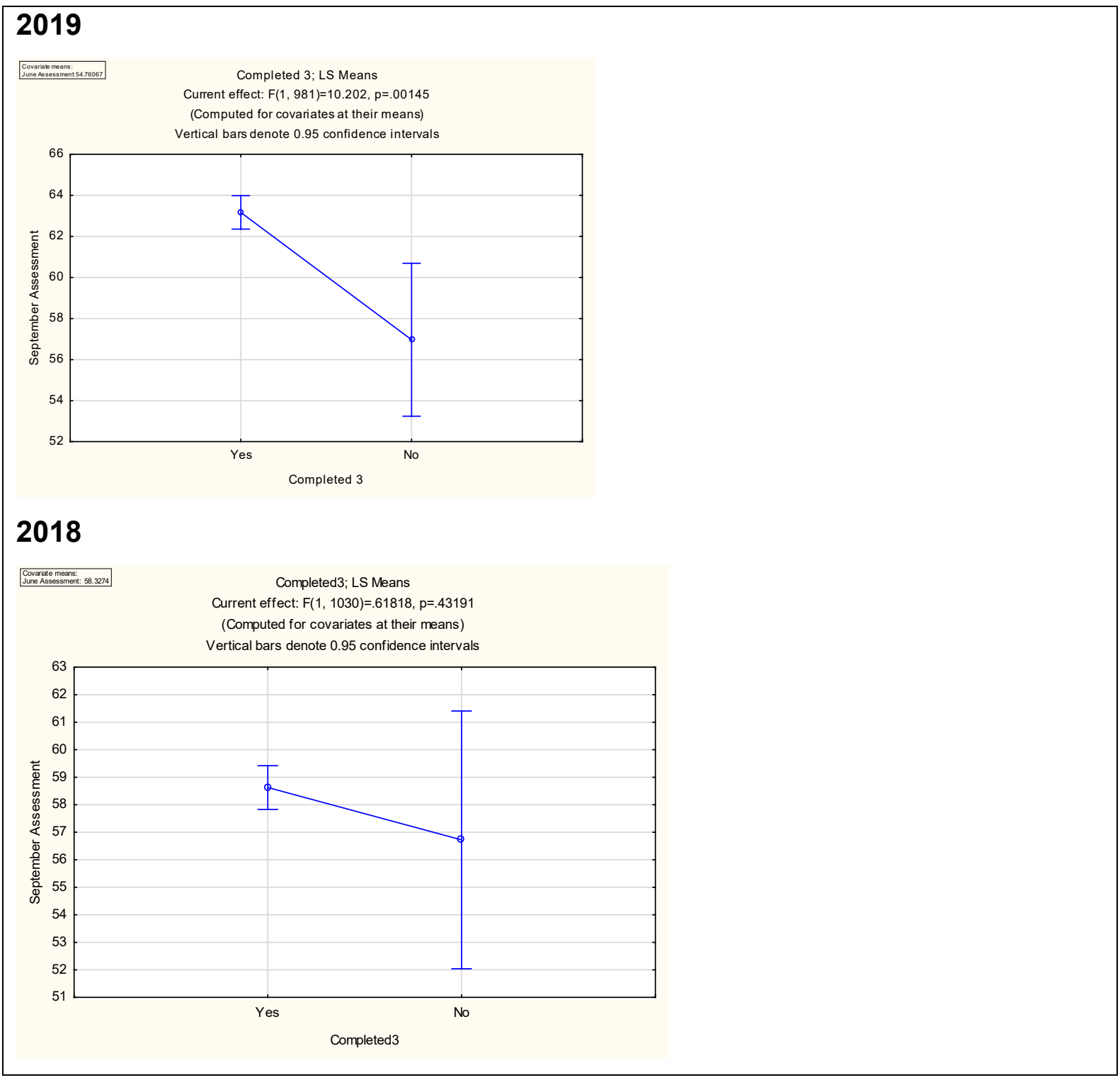

Figure 5: ANOVA results (controlling for previous main assessment mark)

Table 6: November main assessment summarised data

\begin{tabular}{|l|c|c|c|}
\hline Completed the formative assessment & N & Mean & Standard deviation \\
\hline $\mathbf{2 0 1 9}$ & 1022 & 55.974 & 19.436 \\
\hline Total & 280 & 56.366 & 18.727 \\
\hline Yes & 742 & 55.825 & 19.707 \\
\hline No & 1012 & 56.043 & 18.684 \\
\hline $\mathbf{2 0 1 8}$ & 373 & 58.416 & 18.977 \\
\hline Total & 639 & 54.658 & 18.385 \\
\hline Yes &
\end{tabular}


Similar to the results above, the ANOVA for the November higher-stakes main assessment, as displayed in Figures 6 and 7, show that the students who participated in the formative assessment received only marginally higher mean marks, with and without controlling for the previous assessments marks. This suggests that students who completed formative assessments that only cover a small portion of the scope of the subsequent higher-stakes assessment only obtained a marginal benefit because of engaging in such assessments in certain aspects. Further analysis as to the specific nature of the formative assessment revealed that this formative

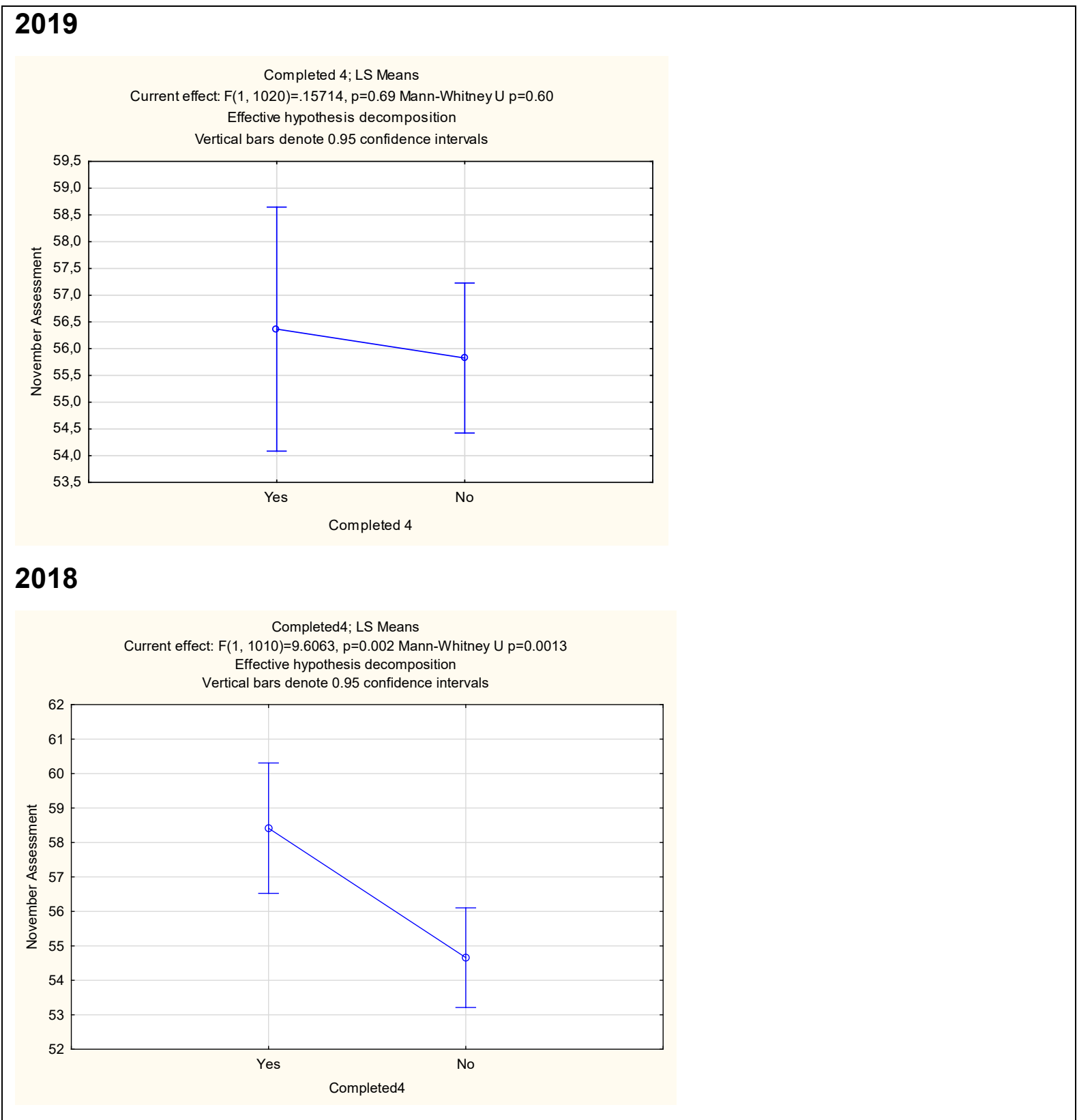

Figure 6: ANOVA results (not controlling for previous main assessment mark) 


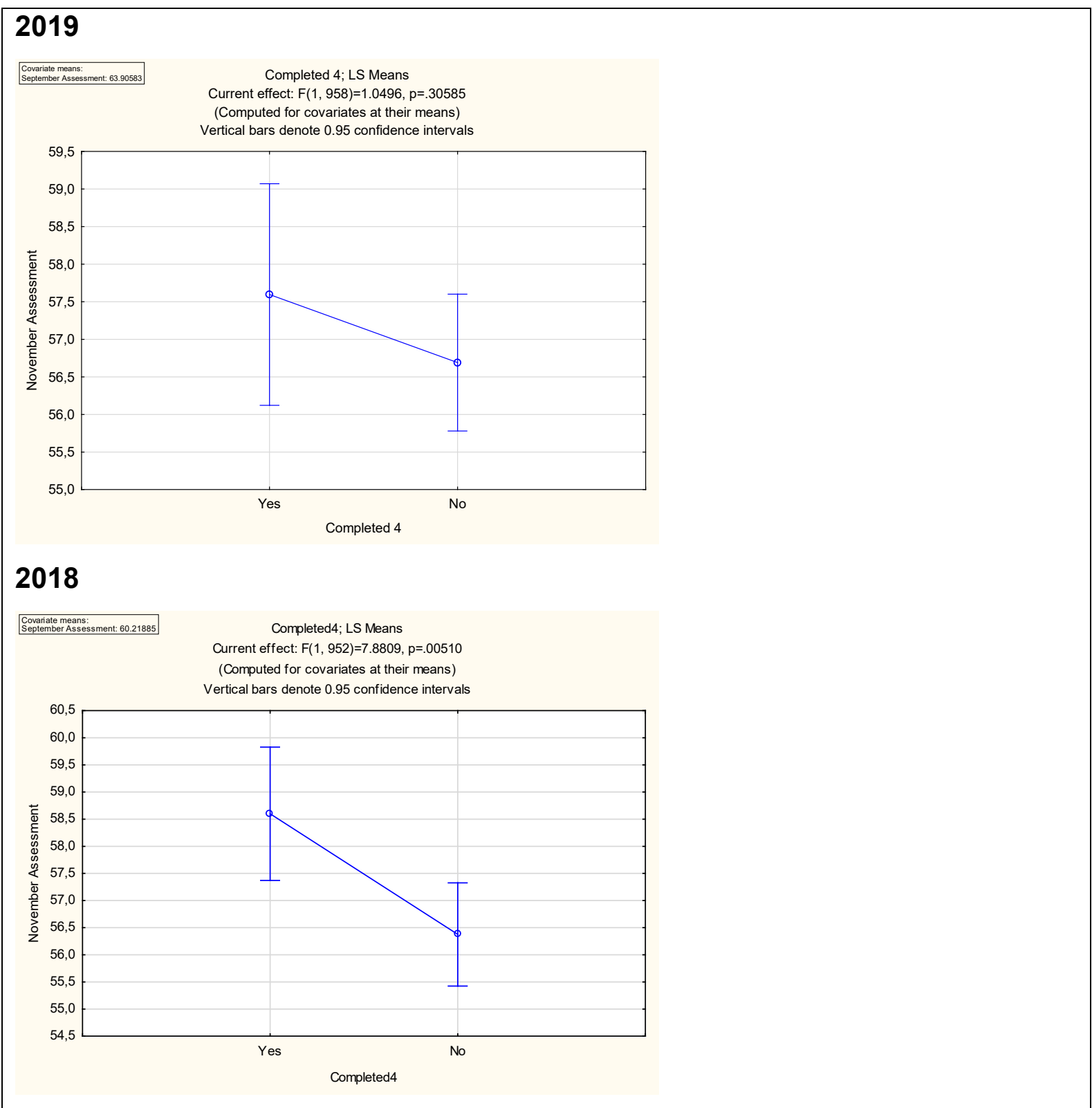

Figure 7: ANOVA results (controlling for previous main assessment mark)

assessment covered two chapters versus 20 chapters being assessed in the higher-stakes main assessment. This differs from the previous low-stakes summative and formative assessments results, which to a significant extent covered the same content as its subsequent higher-stakes main assessment. This limited scope was, however, consistent with the low-stakes summative assessment in August. This provides context into understanding that formative and low-stakes assessments are beneficial to a more significant degree if they cover larger portions of the curriculum. Furthermore, if they do not cover a large scope of the subsequent higher-stakes assessment, then a low-stakes summative assessment appears to have a greater impact in terms of achieving higher participation and having an influence on achieving higher marks in a subsequent higher-stakes assessment. 


\section{Overall summary}

As indicated in Table 7, the results are mixed as to whether completing a formative assessment prior to a main higher-stakes summative assessment had a significant impact on a student's marks. The findings suggest that further investigation is required as to why students choose to engage or not engage in the use of formative assessments and low-stakes summative assessments prior to assessments. The findings thus support on an overall basis that although the nature of formative or low-stakes summative assessment appears to influence the potential benefit of the assessment, the scope of these assessments may make a more significant contribution to the impact of these assessments on higher-stakes main assessments. The findings also suggest that adding an element of stakes in the form of the assessment counting for marks had a significant impact on the participation level of low-stakes assessments, as well as the value added from participation in these assessments for future higher-stakes assessments.

Table 7: Summary of the results for RQ2 and RQ3

\begin{tabular}{|l|l|}
\hline \multicolumn{1}{|c|}{ Period and type of assessment } & Answer to research question \\
\hline March formative and summative assessments (RQ2) & Yes \\
\hline May and June summative assessments (RQ3) & Yes \\
\hline $\begin{array}{l}\text { May and June summative assessments controlling for the March } \\
\text { assessment (RQ3) }\end{array}$ & Yes \\
\hline August and September summative assessments (RQ3) & Yes \\
\hline $\begin{array}{l}\text { August and September summative assessments controlling for } \\
\text { the June assessment (RQ3) }\end{array}$ & Yes \\
\hline October formative and November summative assessment (RQ2) & No \\
\hline $\begin{array}{l}\text { October formative and November summative assessment } \\
\text { controlling for the September assessment (RQ2) }\end{array}$ & No \\
\hline
\end{tabular}

It is suggested, based on the findings, that students should be given the discretion to complete formative assessments as overall the findings indicate that students are able to compensate for the non-completion of a formative or low-stakes summative assessment prior to a higher-stakes main summative assessment by potentially employing alternative learning methods.

\section{LIMITATIONS OF THE STUDY}

This study only included the 2018 and 2019 Financial Accounting 188 students at one university. Their view and participation, based on their social background and field of study, could potentially be different from those of students in other disciplines or from different social backgrounds. These limitations, however, create opportunities for future research in this field specifically focused on the use of formative and low-stakes summative assessments in higher education. 


\section{CONCLUSION}

In understanding the impact of low-stakes formative and summative assessments on higherstakes summative assessments, this study followed the approach of analysing the participation in either a formative assessment that did not count for marks or a low-stakes summative assessment immediately prior to a higher-stakes summative assessment. The study found that, consistent with the existing literature, increased levels of student participation in low-stakes summative assessments had a significant positive relationship with student performance in higher-stakes summative assessments only in certain scenarios, although the nature of either online formative assessments not counting for marks or online summative low-stakes assessments did not have a significant influence on the value added by participation in the assessment. The findings suggest that the scope and contribution to the final marks of the formative assessment play a significant role in the effectiveness of low-stakes formative and summative assessments in preparation for higher-stakes summative assessments. This provides context for understanding that formative and low-stakes assessments are beneficial to a more significant degree if they cover larger portions of the curriculum. Furthermore, if they do not cover a large scope of the subsequent higher-stakes assessment, then a low-stakes summative assessment appears to have a greater impact in terms of achieving higher participation and having an influence on achieving higher marks in a subsequent higher-stakes assessment. The findings also show that the quantity of low-stakes assessments does not necessarily need to be increased to improve the effectiveness of these interventions; instead, particular focus should be placed on ensuring that formative assessments sufficiently cover the scope of higher-stakes summative assessments if the intended purpose of these assessments is to assist in improving marks in higher-stakes assessments.

The findings further suggest that having a small stake in terms of an assessment's contribution to the final mark versus no stake had a significant impact on the students' participation levels, as well as potential value added from participation in such assessments for the purpose of future assessments.

The findings therefore suggest that all interventions are not equal contributors to student success; noting that although the intention of adding more formative and low-stakes summative assessments may be to help improve marks, this may not always be the case. The implications of these findings therefore provide a clearer direction that could be explored in the future and integrated into the educational policymaking process and strategic planning to develop tools to assist in improving student performance in higher-stakes summative assessments. 


\section{NOTE}

1. A main assessment is defined as an assessment that contributes 15 per cent of more to a student's final mark.

\section{REFERENCES}

Aisbitt, S. and A. Sangster. 2005. "Using Internet-Based On-Line Assessment: A Case Study." Accounting Education: An International Journal 14(4): 383-394.

Ayala, C. C., R. J. Shavelson, M. Araceli Ruiz-Primo, P. R. Brandon, Y. Yin, E. M. Furtak, D. B. Young, and M. K. Tomita. 2008. "From Formal Embedded Assessments to Reflective Lessons: The Development of Formative Assessment Studies." Applied Measurement in Education 21(4): 315334.

Biggs, J. 1999. Teaching for Quality Learning at University. Buckingham: Society for Research into Higher Education \& Open University Press.

Black, P. and D. Wiliam. 2010. "Inside the Black Box: Raising Standards through Classroom Assessment." Phi Delta Kappan 92(1): 81-90.

Boud, D. 1988. Developing Student Autonomy in Learning. London: Kogan Page.

Brooks, J. 2018. "Practice Makes Perfect: Student Experience Matters Most.” https://medium.com/ communityworksjournal/practice-makes-perfect-f6246720f43b.

Carrillo-De-La-Peña, M. T., E. Baillès, X. Caseras, À. Martínez, G. Ortet, and J. Pérez. 2009. "Formative Assessment and Academic Achievement in Pre-Graduate Students of Health Sciences." Advances in Health Sciences Education 14(1): 61-67.

Curtis, S. M. 2011. "Formative Assessment in Accounting Education and Some Initial Evidence on its Use for Instructional Sequencing." Journal of Accounting Education 29(4): 191-211.

Dixson, D. D. and F. C. Worrell. 2016. "Formative and Summative Assessment in the Classroom." Theory into Practice 55(2): 153-59.

Dunn, K. E. and S. W. Mulvenon. 2009. "A Critical Review of Research on Formative Assessment: The Limited Scientific Evidence of the Impact of Formative Assessment in Education." Practical Assessment, Research and Evaluation 14(7): 1-11.

Elton, L. and B. Johnston. 2002. Assessment in Universities: A Critical Review of Research. York: LTSN Generic Centre.

Gardner, J. 2010. "Developing Teacher Assessments: An Introduction." In Developing Teacher Assessment, ed. J. Gardner, W. Harlen, L. Hayward, G. Stobart, and M. Montgomery, 1-11. Maidenhead: McGraw-Hill/Open University Press.

Gibbs, G. and C. Simpson. 2005. "Conditions Under Which Assessment Supports Students' Learning." Learning and Teaching in Higher Education 1: 3-31.

Heywood, J. 2000. Assessment in Higher Education: Student Learning, Teaching, Programmes and Institutions. London: Jessica Kingsley.

Holroyd, C. 2000. “Are Assessors Professional?” Active Learning in Higher Education 1(1): 28-44.

Khairil, L. F. and S. E. Mokshein. 2018. "21 $1^{\text {st }}$-Century Assessment: Online Assessment." International Journal of Academic Research in Business and Social Sciences 8(1): 659-672.

Knight, P. T. 2001. A Briefing on Key Concepts: Formative and Summative, Criterion and NormReferenced Assessment. York: Learning and Teaching Support Network (LTSN) Generic Centre.

Marriott, P. and A. Lau. 2008. "The Use of On-Line Summative Assessment in an Undergraduate Financial Accounting Course.” Journal of Accounting Education 26(2): 73-90.

Murphy, D. P. and K. G. Stanga. 1994. "The Effects of Frequent Testing in an Income Tax Course: An Experiment." Accounting Education: An International Journal 6(2): 279-91.

Nicol, D. J. and D. Macfarlane-Dick. 2006. "Formative Assessment and Self-Regulated Learning: A 
Model and Seven Principles of Good Feedback.” Studies in Higher Education 31(2): 199-218.

Qadir, J., A.-E. M. Taha, Y. K. Lim, A. Al-Faqaha, M. Imran, J. Ponciano, and S. Hussain. 2020. "Leveraging the Force of Formative Assessment \& Feedback for Effective Engineering Education." https://edarxiv.org/a4d5q.

Ramsden, P. 1992. Learning to Teach in Higher Education. London: Routledge.

Rowntree, D. 1985. Developing Courses for Students. London: McGraw-Hill.

Scriven, M. 1967. "The Methodology of Evaluation." In Perspectives of Curriculum Evaluation, ed. R. W. Tyler, R. M. Gagné, and M. Scriven, Vol. 1, 39-83. Chicago: Rand McNally.

Trotter, E. 2006. "Student Perceptions of Continuous Summative Assessment." Assessment and Evaluation in Higher Education 31(5): 505-521.

Velan, G. M., P. Jones, H. P. McNeil, and R. K. Kumar. 2008. "Integrated Online Formative Assessments in the Biomedical Sciences for Medical Students: Benefits for Learning." BMC Medical Education 8: 1-11.

Wiggins, G. P. 1998. Educative Assessment: Designing Assessments to Inform and Improve Student Performance. San Francisco: Jossey-Bass.

Wiliam, D. 2006. "Formative Assessment: Getting the Focus Right." Educational Assessment 11(3-4): 283-289. 